\title{
The Discrepancy between Radiographically- assessed and Self-recognized Hallux Valgus in a Large Population-based Cohort
}

Takumi Matsumoto ( $\nabla$ matumot-tky@umin.ac.jp)

The University of Tokyo

Junya Higuchi

The University of Tokyo

Yuji Maenohara

The University of Tokyo

Song Ho Chang

The University of Tokyo

Toshiko lidaka

The University of Tokyo

Chiaki Horii

The University of Tokyo

Hiroyuki Oka

The University of Tokyo

Shigeyuki Muraki

The University of Tokyo

Hiroshi Hashizume

Wakayama Medical University

Hiroshi Yamada

Wakayama Medical University

Munehito Yoshida

Wakayama Medical University

Kozo Nakamura

Towa Hospital

Sakae Tanaka

The University of Tokyo

Noriko Yoshimura

The University of Tokyo 
Keywords: Hallux valgus, hallux valgus interphalangeus, prevalence, radiograph, self-recognition

Posted Date: August 26th, 2021

DOI: https://doi.org/10.21203/rs.3.rs-827520/v1

License: (1) (1) This work is licensed under a Creative Commons Attribution 4.0 International License. Read Full License

Version of Record: A version of this preprint was published at BMC Musculoskeletal Disorders on January 4th, 2022. See the published version at https://doi.org/10.1186/s12891-021-04978-z. 


\section{Abstract}

Background: There has been a paucity of literature revealing the discrepancy between self-recognition about hallux valgus (HV) and radiographically-evaluated foot configuration.

Questions/Purposes: (1) Is there a discrepancy between radiographically-assessed and self-recognized $\mathrm{HV}$ in the general population? (2) What factors affect the self-recognition of HV in the general population?

Methods: The fifth survey of the Research on Osteoarthritis/Osteoporosis against Disability study involved 1996 participants who had undergone anterior-posterior radiography of bilateral feet and answered an interviewer-administered questionnaire on self-recognition of HV. Measurements of the HV angle (HVA) and interphalangeal angle of the hallux (IPA) were performed using radiographs. After univariate comparison of the participant backgrounds and radiographic measurements between participants with or without self-recognition of HV, multivariable logistic regression analysis was conducted in order to reveal independent factors affecting self-recognition.

Results: The mean HVA and IPA were $16.8^{\circ}$ and $15.4^{\circ}$, respectively. Significant difference was found between the prevalence of radiographically-assessed and self-recognized HV $(29.8 \%$ vs. $16.5 \%, p<$ 0.0001). The prevalence of self-recognized HV increased with the progression of HV severity from a single-digit percentage (normal grade, $\mathrm{HVA}<20^{\circ}$ ) up to $100 \%$ (severe grade, $\mathrm{HVA} \geq 40^{\circ}$ ). A multivariable logistic regression analysis demonstrated that HVA and female sex were independent positive factors for self-recognition of HV (HVA [per $1^{\circ}$ increase]: OR, 1.20; 95\% Cl, 1.18-1.22; $\mathrm{p}<0.0001$; and female sex [vs. male sex]: OR, 3.17; 95\% Cl, 2.14-4.73; $p<0.0001)$.

Conclusions: There was a significant discrepancy between radiographically-assessed and self-recognized HV which narrowed with the progressing severity of HV. HVA and female sex were independent positive factors for self-recognition of HV.

\section{Background}

Hallux valgus (HV) is a common foot deformity associated with a laterally-deviated hallux and a medially-prominent first metatarsal head [1]. HV causes pain and difficulties in finding properly fitted footwear, and correlates with functional disability and elevated risk for falls in elderly adults [2, 3]. A pooled analysis on $\mathrm{HV}$ prevalence provided an estimate of $23 \%$ in the general population aged between 18 and 65 years [4]. While differences in race, footwear habits, and regions have been known to affect the true prevalence of HV [5-7], the reported prevalence is also affected by research methods, including sampling methodology, study quality, and method of HV diagnosis. For example, a systematic review of the literature on $\mathrm{HV}$ prevalence demonstrated that the studies reporting HV prevalence by means of clinical examination showed a higher prevalence than those that used self-reporting with interviews or questionnaires [4]. However, there has been a paucity of literature revealing the discrepancy between selfrecognition about $\mathrm{HV}$ and radiographically-evaluated foot configuration in the same cohort. Knowing the gap between self-recognition about HV and actual deformity in the general population will not only 
provide a better interpretation of previous surveys on $\mathrm{HV}$ prevalence, but will also help to construct strategies for preventing HV. Therefore, the present study was aimed for investigating the relationship between HV self-recognition and radiographically-assessed hallux deformity, and to clarify the factors influencing self-recognition of HV in the general Japanese population.

\section{Patients \& Methods}

\section{Study design}

The present study was performed as part of the fifth survey of the Research on Osteoarthritis/Osteoporosis Against Disability (ROAD) study. The details of the ROAD study have been previously described [8]. It is a nationwide prospective study established in 2005 aiming for aggregating the epidemiological data about locomotorium diseases, especially osteoarthritis (OA) and osteoporosis. It consists of three local residents cohorts from the following three different regions in Japan: an urban region (Itabashi district, Tokyo); a mountainous region (Hidakagawa city, Wakayama); and a coastal region (Taiji city, Wakayama). The resident registration lists of the communities were used for recruitment of the participants. The fifth survey was performed during 2018-2019 in the mountainous and coastal regions with 2386 participants. A total of 827 subjects in the mountainous region and 1169 participants in the coastal region had radiographs of both feet and had answered interviewer-administered questionnaires; therefore, their data were used for analysis. The interviewer-administered questionnaire consisted of information regarding the participants' personal medical history, family history, physical activity, and pain in the joint, among others. With respect to the foot, the participants were asked if they thought they had HV, separately for their left and right feet. The participants who answered yes to this question were further interviewed on the following items: 1) since when they had been aware of having $\mathrm{HV}$; 2) whether their HV was accompanied by pain; and 3) if there was a history of hospital visit for HV.

\section{Radiographic assessment}

Anterior-posterior radiographs of the bilateral feet of each participant were obtained in the supine position with the plantar aspect of their feet resting on the image receptor and with the beam angled approximately $15^{\circ}$ posteriorly towards the calcaneus, by licensed radiography technicians. The $\mathrm{HV}$ angle (HVA) and the interphalangeal angle of the hallux (IPA) were measured in the foot radiographs as the angle between two longitudinal axes of the first metatarsal and the proximal phalanx [9] and the angle between two longitudinal axes of the proximal phalanx and the distal phalanx [10], respectively. All measurements were achieved by an independent orthopedist who was a board-certified member of the Japanese Orthopedic Association in order to eliminate the influence of inter-observer variability. The grade of HV severity was classified using the HVA, according to the Japanese Orthopedic Society criteria, as follows: $<20^{\circ}$, normal; $20-29^{\circ}$, mild; $30-39^{\circ}$, moderate; and $\geq 40^{\circ}$, severe [11]. The total valgus deformity of the hallux (TVDH) was figured by adding the HVA and IPA [10].

\section{Statistics}


Continuous variables were expressed as mean \pm standard deviation. Proportions were presented as counts and percentages. Pearson's correlation coefficients were applied to examine the relationship between the HVA and IPA. Comparisons of participants' backgrounds and radiographic parameters between groups (men vs. women, or participants with self-recognition about HV vs. those without) were performed using appropriate statistical methods as described below. The Student's t-test was used for comparison of continuous variables. The chi-square test or Fisher's exact test was used for comparison of proportions between groups followed by adjusted residual analysis in cases with significant differences. Multivariable logistic regression analysis was performed to clarify the independent factors influencing self-recognition of HV. All variables having a p-value of less than 0.05 in univariate analysis were put into the model. Statistical differences were considered significant when a p-value was less than 0.05. The JMP12 statistical software (SAS Institute Inc., Cary, NC, USA) was used for all statistical analyses.

\section{Results}

The participant characteristics were summarized in Table 1. In the whole cohort, the percentage of participants who had at least one radiographic $\mathrm{HV}$ was $39.0 \%$, with a significant difference between men and women $(22.8 \%$ vs. $46.0 \%$, $p<0.05)$. Bilateral HV was detected in 423 participants $(21.2 \%)$, with a significant difference between men and women $(10.2 \%$ vs. $26.5 \%, p<0.05)$. 
Table 1

Participants' characteristics and comparisons between men and women

\begin{tabular}{|c|c|c|c|c|}
\hline & $\begin{array}{l}\text { Total } \\
(n=1996)\end{array}$ & $\begin{array}{l}\text { Men } \\
(n=654)\end{array}$ & $\begin{array}{l}\text { Women } \\
(n=1342)\end{array}$ & $P$-value \\
\hline Age (years) & $64.2 \pm 12.7$ & $63.9 \pm 13.7$ & $64.4 \pm 12.1$ & 0.35 \\
\hline \multicolumn{5}{|l|}{ Age distribution (n [\%]) } \\
\hline$<39$ & $64(3.2 \%)$ & $29(4.4 \%)^{*}$ & $35(2.6 \%)$ & \multirow[t]{6}{*}{$<0.0001$} \\
\hline $40-49$ & $191(9.6 \%)$ & $72(11.0 \%)$ & $119(8.9 \%)$ & \\
\hline $50-59$ & $348(17.4 \%)$ & $102(15.6 \%)$ & $246(18.3 \%)$ & \\
\hline $60-69$ & $593(29.7 \%)$ & $193(29.5 \%)$ & $400(29.8 \%)$ & \\
\hline $70-79$ & $555(27.8 \%)$ & $165(25.2 \%)$ & $390(29.0 \%)$ & \\
\hline $80 \leqq$ & 245 (12.2\%) & $93(14.2 \%)$ & 152 (11.3\%) & \\
\hline Height (cm) & $158.0 \pm 9.1$ & $167.1 \pm 6.7$ & $153.5 \pm 6.7$ & $<0.0001$ \\
\hline Body weight (kg) & $57.0 \pm 11.6$ & $66.0 \pm 11.1$ & $52.6 \pm 9.0$ & $<0.0001$ \\
\hline Residing in the coastal area & $1169(58.6 \%)$ & $377(57.7 \%)$ & $792(59.0 \%)$ & 0.56 \\
\hline Body mass index $\left(\mathrm{kg} / \mathrm{m}^{2}\right)$ & $22.7 \pm 3.5$ & $23.6 \pm 3.3$ & $22.3 \pm 3.5$ & $<0.0001$ \\
\hline Radiographic HV in at least one foot & $766(39.0 \%)$ & $149(22.8 \%)$ & $617(46.0 \%)$ & $<0.0001$ \\
\hline Radiographic HV in both feet & $423(21.2 \%)$ & $67(10.2 \%)$ & $356(26.5 \%)$ & $<0.0001$ \\
\hline \multicolumn{5}{|l|}{ Abbreviations: HV, hallux valgus } \\
\hline
\end{tabular}

The radiographic parameters of the 3992 feet and their sex-based differences were summarized in Table 2. The radiographic HV was found in $29.8 \%$ (1189 out of 3992 feet), with a significant difference between men and women $(16.5 \%$ vs. $36.3 \%, p<0.0001)$. The mean HVA was $16.8 \pm 7.6^{\circ}$, with a significant difference between men and women $\left(14.4 \pm 6.2^{\circ}\right.$ vs. $\left.18.0 \pm 7.9^{\circ}, p<0.0001\right)$. The significantly higher value of HVA in women compared to men was consistent even when separated by age brackets. The mean IPA was $15.4 \pm 5.6^{\circ}$, with significantly higher values in men than in women $\left(16.6 \pm 4.8^{\circ}\right.$ vs. $14.9 \pm 5.8^{\circ}, p<$ 0.0001). The significantly higher value of IPA in men compared to women was limited in those over 50 years of age, when separated by age brackets. A moderate negative correlation between HVA and IPA was found $(r=-0.4308, p<0.0001)$. The IPA accounted for $48.9 \pm 17.6 \%$ of TVDH in average, with a significantly higher contribution in men compared to women $(54.5 \pm 14.6 \%$ vs. $46.2 \pm 18.3 \%$, $p<0.0001)$. With respect to HV severity, 1308 feet in men were classified as follows: normal, 1092 feet (83.5\%); mild, 188 feet (14.4\%); moderate, 22 feet (1.7\%); and severe, 6 feet (0.5\%). Similarly, 2684 feet in women were 
classified as follows: normal, 1711 feet (63.7\%); mild, 740 feet (27.6\%); moderate, 200 feet (7.5\%); and severe, 33 feet (1.2\%). HV severity had a higher prevalence of normal grade in men, and a higher prevalence of mild, moderate, and severe grades in women. 
Table 2

Comparisons of radiographic measurements, prevalence of radiographically-assessed hallux valgus and self-recognition on hallux valgus, and grades of hallux valgus severity between the feet of men and women

\begin{tabular}{|c|c|c|c|c|c|}
\hline & & $\begin{array}{l}\text { Total } \\
(n=3992)\end{array}$ & $\begin{array}{l}\text { Men } \\
(n=1308)\end{array}$ & $\begin{array}{l}\text { Women } \\
(n=2684)\end{array}$ & $P$-value \\
\hline \multirow[t]{7}{*}{$\operatorname{HVA}\left({ }^{\circ}\right)$} & All & $16.8 \pm 7.6$ & $14.4 \pm 6.2$ & $18.0 \pm 7.9$ & $\begin{array}{l}< \\
0.0001\end{array}$ \\
\hline & Age $<39$ & $15.3 \pm 5.0$ & $13.6 \pm 4.7$ & $16.7 \pm 4.8$ & 0.0004 \\
\hline & Age $40-49$ & $16.4 \pm 6.1$ & $14.1 \pm 5.3$ & $17.9 \pm 6.2$ & $<.0001$ \\
\hline & Age $50-59$ & $16.5 \pm 6.6$ & $13.7 \pm 5.0$ & $17.6 \pm 6.8$ & $<.0001$ \\
\hline & Age $60-69$ & $17.0 \pm 7.5$ & $14.7 \pm 5.9$ & $18.2 \pm 7.9$ & $\begin{array}{l}< \\
0.0001\end{array}$ \\
\hline & Age $70-79$ & $17.1 \pm 8.4$ & $14.6 \pm 7.0$ & $18.1 \pm 8.7$ & $\begin{array}{l}< \\
0.0001\end{array}$ \\
\hline & Age $80 \leqq$ & $16.6 \pm 8.7$ & $14.4 \pm 7.2$ & $17.9 \pm 9.2$ & $\stackrel{<}{0.0001}$ \\
\hline \multirow[t]{7}{*}{$\operatorname{IPA}\left({ }^{\circ}\right)$} & All & $15.4 \pm 5.6$ & $16.6 \pm 4.8$ & $14.9 \pm 5.8$ & $\begin{array}{l}< \\
0.0001\end{array}$ \\
\hline & Age $<39$ & $17.3 \pm 4.2$ & $18.0 \pm 3.8$ & $16.7 \pm 4.4$ & 0.0501 \\
\hline & Age $40-49$ & $16.6 \pm 4.5$ & $16.4 \pm 4.6$ & $16.7 \pm 4.5$ & 0.6864 \\
\hline & Age $50-59$ & $16.3 \pm 4.7$ & $17.1 \pm 4.5$ & $16.0 \pm 4.8$ & 0.0016 \\
\hline & Age $60-69$ & $15.0 \pm 5.5$ & $16.5 \pm 4.9$ & $14.3 \pm 5.7$ & $\begin{array}{l}< \\
0.0001\end{array}$ \\
\hline & Age $70-79$ & $14.9 \pm 6.1$ & $16.4 \pm 4.9$ & $14.2 \pm 6.4$ & $\begin{array}{l}< \\
0.0001\end{array}$ \\
\hline & Age $80 \leqq$ & $15.0 \pm 6.2$ & $16.1 \pm 5.2$ & $14.3 \pm 6.7$ & 0.0007 \\
\hline \multicolumn{2}{|c|}{ Contribution of IPA to TVDH (\%) } & $48.9 \pm 17.6$ & $54.5 \pm 14.6$ & $46.2 \pm 18.3$ & $\begin{array}{l}< \\
0.0001\end{array}$ \\
\hline HV grade (feet [\%]) & Normal & $\begin{array}{l}2803 \\
(70.2 \%)\end{array}$ & $\begin{array}{l}1092 \\
(83.5 \%)^{*}\end{array}$ & $\begin{array}{l}1711 \\
(63.8 \%)\end{array}$ & $<.0001$ \\
\hline
\end{tabular}

Abbreviations: HVA, hallux valgus angle; IPA, interphalangeal angle; TVDH, total valgus deformity of the hallux; HV, hallux valgus

* Significantly higher proportion on comparison between men and women, as detected on chi-square test and subsequent adjusted residual analysis 


\begin{tabular}{|c|c|c|c|c|}
\hline & $\begin{array}{l}\text { Total } \\
(n=3992)\end{array}$ & $\begin{array}{l}\text { Men } \\
(n=1308)\end{array}$ & $\begin{array}{l}\text { Women } \\
(n=2684)\end{array}$ & $P$-value \\
\hline Mild & $928(23.2 \%)$ & $188(14.4 \%)$ & $\begin{array}{l}740 \\
(27.6 \%)^{\star}\end{array}$ & \\
\hline Moderate & $222(5.6 \%)$ & $22(1.7 \%)$ & $200(7.5 \%)^{\star}$ & \\
\hline Severe & $39(1.0 \%)$ & $6(0.5 \%)$ & $33(1.2 \%)^{\star}$ & \\
\hline Prevalence of radiographic HV (feet [\%]) & $\begin{array}{l}1189 \\
(29.8 \%)\end{array}$ & $216(16.5 \%)$ & $973(36.3 \%)$ & $<$. \\
\hline $\begin{array}{l}\text { Prevalence of HV self-recognition (feet } \\
{[\%] \text { ) }}\end{array}$ & $657(16.5 \%)$ & $71(5.4 \%)$ & $586(21.8 \%)$ & $<.0001$ \\
\hline \multicolumn{5}{|c|}{$\begin{array}{l}\text { Abbreviations: HVA, hallux valgus angle; IPA, interphalangeal angle; TVDH, total valgus deformity of } \\
\text { the hallux; HV, hallux valgus }\end{array}$} \\
\hline \multicolumn{5}{|c|}{$\begin{array}{l}\text { * Significantly higher proportion on comparison between men and women, as detected on chi-square } \\
\text { test and subsequent adjusted residual analysis }\end{array}$} \\
\hline
\end{tabular}

The percentage of feet recognized subjectively as HV by participants was $16.5 \%$ (657 out of 3992 feet) overall, which was significantly lower than the prevalence of radiographically-assessed HV $(p<0.0001)$. A significant difference in the percentage of $\mathrm{HV}$ self-recognition between men and women was observed ( $5.4 \%$ vs. $21.8 \%, p<0.0001)$. The percentage of HV self-recognition increased with an increase in HVA or HV severity (Fig. 1 and Table 3). Among the feet subjectively recognized as HV, 7 out of 71 feet (9.9\%) in men and 130 out of 583 feet $(22.3 \%)$ in women were accompanied by pain. The participants reported recognizing $\mathrm{HV}$ an average of 17.3 years ago (range, $1-70$ years). Among the 409 participants with HV self-recognition, $48(11.7 \%)$ had a history of visiting the hospital for HV, and one (2.4\%) had a history of surgery for HV. 
Table 3

Comparisons of participant characteristics, radiographic measurements, and grades of hallux valgus severity between feet with and without self-recognized hallux valgus

\begin{tabular}{|c|c|c|c|c|c|c|}
\hline & \multicolumn{2}{|l|}{ Men } & $\begin{array}{l}P \\
\text { value }\end{array}$ & \multicolumn{2}{|l|}{ Women } & $P$-value \\
\hline & \multicolumn{3}{|c|}{ Self-recognition } & \multicolumn{3}{|c|}{ Self-recognition } \\
\hline & $\begin{array}{l}\text { Yes }(n= \\
71)\end{array}$ & $\begin{array}{l}\text { No }(n= \\
1237)\end{array}$ & & $\begin{array}{l}\text { Yes }(n= \\
586)\end{array}$ & $\begin{array}{l}\text { No }(n= \\
2098)\end{array}$ & \\
\hline Age (years) & $\begin{array}{l}67.6 \pm \\
11.2\end{array}$ & $63.6 \pm 13.8$ & 0.0183 & $65.9 \pm 10.6$ & $64.0 \pm 12.5$ & 0.0006 \\
\hline Height (cm) & $\begin{array}{l}166.1 \pm \\
7.6\end{array}$ & $167.2 \pm 6.6$ & 0.1824 & $153.0 \pm 6.6$ & $153.7 \pm 6.3$ & 0.0367 \\
\hline Body weight $(\mathrm{kg})$ & $\begin{array}{l}64.6 \pm \\
11.1\end{array}$ & $66.1 \pm 11.1$ & 0.2811 & $52.6 \pm 8.3$ & $52.6 \pm 9.2$ & 0.9934 \\
\hline $\begin{array}{l}\text { Body mass index } \\
\left(\mathrm{kg} / \mathrm{m}^{2}\right)\end{array}$ & $23.4 \pm 3.6$ & $23.6 \pm 3.3$ & 0.6486 & $22.5 \pm 3.1$ & $22.3 \pm 3.6$ & 0.2934 \\
\hline $\operatorname{HVA}\left({ }^{\circ}\right)$ & $23.8 \pm 9.6$ & $13.8 \pm 5.4$ & $\begin{array}{l}< \\
0.0001\end{array}$ & $26.0 \pm 8.9$ & $15.7 \pm 5.9$ & $\begin{array}{l}< \\
0.0001\end{array}$ \\
\hline $\operatorname{IPA}\left({ }^{\circ}\right)$ & $12.9 \pm 8.7$ & $16.8 \pm 4.4$ & $\begin{array}{l}< \\
0.0001\end{array}$ & $11.0 \pm 7.4$ & $16.0 \pm 4.8$ & $\begin{array}{l}< \\
0.0001\end{array}$ \\
\hline \multicolumn{7}{|c|}{ HV grade (feet [\%]§) } \\
\hline Normal & $25(2.3 \%)$ & $\begin{array}{l}1067 \\
(97.7 \%)^{*}\end{array}$ & \multirow[t]{4}{*}{$\begin{array}{l}< \\
0.0001\end{array}$} & $141(8.2 \%)$ & $\begin{array}{l}1570 \\
(91.8 \%)^{*}\end{array}$ & \multirow[t]{4}{*}{$<0.0001$} \\
\hline Mild & $\begin{array}{l}31 \\
(16.5 \%)^{*}\end{array}$ & $157(83.5 \%)$ & & $\begin{array}{l}252 \\
(34.1 \%)^{*}\end{array}$ & $488(65.9 \%)$ & \\
\hline Moderate & $\begin{array}{l}9 \\
(41.0 \%)^{*}\end{array}$ & $13(59.0 \%)$ & & $\begin{array}{l}160 \\
(80.0 \%)^{*}\end{array}$ & $40(20.0 \%)$ & \\
\hline Severe & $\begin{array}{l}6 \\
(100 \%)^{*}\end{array}$ & $0(0.0 \%)$ & & $\begin{array}{l}33 \\
(100 \%)^{*}\end{array}$ & $0(0.0 \%)$ & \\
\hline
\end{tabular}

HVA, hallux valgus angle; IPA, interphalangeal angle; HV, hallux valgus

§ Percentage was calculated as the ratio between those with and without self-recognition, in each grade of HV severity.

* Significantly higher proportion detected on the adjusted residual analysis.

The comparison of participant characteristics and radiographic measurements between those with HV self-recognition and those without are summarized in Table 3. Those with self-recognition were significantly older, in both sexes (men: $67.6 \pm 11.2$ years vs. $63.6 \pm 13.8$ years, $p=0.0183$; women: $65.9 \pm$ 10.6 years vs. $64.0 \pm 12.5$ years, $p=0.0006$ ), and height was significantly lower only in women with self- 
recognition ( $153.0 \pm 6.6 \mathrm{~cm}$ vs. $153.7 \pm 6.3 \mathrm{~cm}, p=0.0367)$ (Table 3). Self-recognized feet had significantly higher HVA and lower IPA than those that were not self-recognized, regardless of sex (HVA: [men] $23.8 \pm 9.6^{\circ}$ vs. $13.8 \pm 5.4^{\circ}, p<0.0001$; [women] $26.0 \pm 8.9^{\circ}$ vs. $15.7 \pm 5.9^{\circ}, p<0.0001$, IPA: [men] 12.9 $\pm 8.7^{\circ}$ vs. $16.8 \pm 4.4^{\circ}, p<0.0001$; [women] $11.0 \pm 7.4^{\circ}$ vs. $\left.16.0 \pm 4.8^{\circ}, p<0.0001\right)$.

A multivariable analysis revealed that HVA and women were independent positive factors of $\mathrm{HV}$ selfrecognition (HVA [per $1^{\circ}$ increase]: OR, 1.20; $95 \% \mathrm{Cl}, 1.18-1.22 ; \mathrm{p}<0.0001$, women [vs. men]: OR, 3.17; $95 \% \mathrm{Cl}, 2.14-4.73 ; \mathrm{p}<0.0001$ ) (Table 4). On the contrary, IPA was detected as an independent negative factor (OR, 0.94; 95\% Cl, 0.92-0.96; $p<0.0001)$.

Table 4

Multivariable logistic regression for self-recognition of hallux valgus.

\begin{tabular}{|llll|}
\hline & Odds ratio & $95 \%$ Cl & P-value \\
\hline Age (per year) & 1.009 & $0.998-1.020$ & 0.0817 \\
\hline Height (per cm) & 1.007 & $0.989-1.027$ & 0.4310 \\
\hline HVA $\left(\right.$ per $\left.^{\circ}\right)$ & 1.201 & $1.181-1.222$ & $<0.0001$ \\
\hline IPA $\left(\right.$ per $\left.^{\circ}\right)$ & 0.941 & $0.921-0.960$ & $<0.0001$ \\
\hline Sex & & & \\
\hline Men & 1.00 & & $<0.0001$ \\
\hline Women & 3.23 & $2.20-4.81$ & \\
\hline HVA, hallux valgus angle; IPA, interphalangeal angle; Cl, confidence interval \\
\hline
\end{tabular}

\section{Discussion}

The present population-based cross-sectional study reported the prevalence of radiographically-assessed and self-recognized HV in approximately 2000 participants and the discrepancy between them. The prevalence of HV self-recognition was almost half that of radiographic HV and increased according to HV severity. The present study also demonstrated that valgus position of the proximal phalanx and female sex, but not interphalangeal HV, were independent positive factors for self-recognition of HV.

The present study demonstrated a $29.8 \%$ (1189 out of 3992 feet) prevalence of radiographically-assessed $\mathrm{HV}$ in two towns, including a mountainous region and a coastal region, which is similar to the investigation by Nishimura et al. reporting a $22.8 \%$ (184 out of 806 feet) prevalence in a single mountainous village from a different prefecture in the same country as ours [12]. A 2010 meta-analysis by Nix et al. including 78 articles written in several different languages reported a pooled prevalence estimate of HV of $23 \%$ in the population aged 18 to 65 , and of $35.7 \%$ in the elderly over 65 years [4]. In 
Japan, where the present survey was conducted, traditional open-toed footwear like sandals and clogs had been preferably worn until the mid-20th century. However, the acceptance of westernized footwear and the declined usage of conventional footwear after World War II have resulted in a marked increase of HV surgeries [13]. Our survey demonstrated that Japan currently embraces a comparable population to other nations having a long-established culture of wearing shoes in having HV.

While the prevalence of $\mathrm{HV}$ varies by population group, ethnicity, geographic location, cultural differences in footwear, or socioeconomic status, methodological differences in investigation could also affect the reported value on prevalence. As for the sampling method, studies covering convenience samples such as people visiting foot clinics with foot problems are more likely to report higher prevalence estimates compared to those studies covering people randomly sampled from the general population[4]. One of the strengths of the present study is that we used population-based cohorts, even though our cohort did not include those who could not visit the survey venue or those who did not agree to the survey, and was thus not perfectly free from selection bias. As for the evaluation methods, the studies using clinical examinations showed a decisively higher prevalence than those using self-reporting measures such as interviews or questionnaires [4]. In a meta-analysis of HV prevalence, Nix et al. reported that only $16 \%$ of studies in their review used diagnostic criterion for HV based on radiographically- or clinically-measured angle, and that the larger the size of the studied population, the less likely it was to adopt radiographic evaluation for $\mathrm{HV}$ and more likely to adopt self-reporting or visual inspection [4]. To our knowledge, there has been no report on HV prevalence using radiographic angular criteria in community-based studies involving over 1,000 subjects.

Another problem to be faced when interpreting reports about HV prevalence is the use of the term "bunion" in questionnaires or interviews. The term "bunion" means the bursitis located at the medial of first metatarsal head caused by irritation with footwear and is sharply distinguished form the term "hallux valgus" which is a morphological deformation of the hallux [14]. However, these two terms are often used synonymously and cause discrepancies between surveys. For example, this kind of discrepancy is well presented as a large difference in HV prevalence between two surveys by Adams et al. in 1999 and Dunn et al. in 2004, respectively $[5,15]$. Adams et al. reported a $0.9 \%$ prevalence of bunions among 63402 persons in the National Health Interview Survey of the USA using questionnaires about whether the questionees had "trouble with bunions" [15]; on the other hand, Dune et al. reported a 37.1\% prevalence of bunion on clinical assessment among 784 randomly-sampled community-dwelling adults in the USA, although they seemed to use the term "bunion" to refer to "hallux valgus" [5]. In Japan, a term corresponding to "bunion" does not exist but a term corresponding to "hallux valgus" does. The condition of bunion is generally stated just as "pain or redness caused by HV"; therefore, our question about "hallux valgus" in the present survey can be regarded as asking simply about "deformity" but not about "symptoms".

The definition of the normal range of HVA also affects HV prevalence. An investigation in Korea by Cho et al. adopted a definition of $\mathrm{HV}$ as $\mathrm{HVA}>15^{\circ}$, which was broader than our definition of $\mathrm{HVA}>20^{\circ}$, and reported a prevalence as high as $64.7 \%$ among community-dwelling subjects aged between 40 and 69

Page $12 / 18$ 
years [16]. If we adopted the same definition of $\mathrm{HV}$ as Cho et al., $\mathrm{HV}$ prevalence in the present study would be $45.2 \%$ in men and $62.7 \%$, which is consistent with their study. The "normal range" of anatomical structures is a terminological conception and often arbitrary. It can be based on the distribution of relevant values among asymptomatic healthy subjects or the general population, prognostic prediction, treatment goals, and so on. HV is asymptomatic in a large part of the population; however, the deformity is clinically considered to be progressive, although there has been no consensus about the cut-off value predicting poor prognosis. Many studies using the HV definition of HVA $>15^{\circ}$ in radiographic assessments are based on the study by Hardy and Clapham in 1951, reporting a mean $15.7^{\circ}$ of HVA among convenient samples, including the staff and students at college [17]; however, it seems too strict to adopt the mean value as a cut-off value between normal and abnormal values. In the present study, there was a great leap in self-recognition between the two groups with HVA of $15-20^{\circ}$ and $20-25^{\circ}(4.3 \%$ vs. $12.8 \%$ in men, and $13.1 \%$ vs. $26.2 \%$ in women); therefore, we consider HVA $>20^{\circ}$ to be valuable as one of the borders between normal and abnormal in terms of its influence on body image.

The prevalence of symptomatic HV was as low as approximately $10 \%$ in the present study, which might still be an overestimation as the presence of pain from $\mathrm{HV}$ was asked only to those participants who had self-recognition of HV. This low prevalence of pain would mean that the majority of HV cases are asymptomatic. Many patients do not visit clinics or seek surgical help until symptoms become troublesome years after they recognize the deformity. A survey of patients aged 20-66 years who were waiting for $\mathrm{HV}$ operation at a single hospital reported that $46 \%$ of the patients had noticed their deformity before they were 20 years old [17]. A cross-sectional investigation in our cohort consisting of communitydwelling adults demonstrated that participants with self-recognition of $\mathrm{HV}$ remembered having their deformity for an average of 17 years, but only $11.7 \%$ of them had a history of visiting the hospital for it. $\mathrm{HV}$ is generally a progressive deformity that can lead to functional disability and an elevated risk of falls in the elderly $[2,3,18]$. Mild deformity can be managed with conservative treatments such as advice on footwear, exercise, and orthosis in order to prevent progressive deformity and pain; however, symptomatic severe deformity regularly requires surgery. Increasing the general awareness of foot with mild HV deformity would help promote prevention of HV deformity.

The HV interphalangeus refers to a laterally deviated distal phalanx of the great toe, which is mainly attributed to its anatomical nature. The IPA was reported to be approximately $13^{\circ}$ on average, among 346 British feet [19]. The HV interphalangeus could be presumed to contribute substantially to the total valgus deviation of the hallux, considering that normal HVA, a lateral deviation of the proximal phalanx against the 1 st metatarsal, is $5^{\circ}$ to $15^{\circ}$ [20]. However, the effect of the $\mathrm{HV}$ interphalangeus on self-recognition of $\mathrm{HV}$ has not been elucidated. Some radiographic studies have described an inverse association between HVA and IPA, which was confirmed in the present study [10,21, 22]. There are two proposed explanations for this inverse relationship $[21,23]$. One explanation is based on the findings from a comparative study of radiographic parameters showing larger IPA in feet with hallux rigidus compared to normal feet or feet in hallux rigidus [23]. The increased stability in the horizontal plane at the metatarsophalangeal joint of hallux rigidus feet would let the laterally diverting force from shoe pressure or muscle activity toward the hallux concentrate at the interphalangeal joint; however, in the unstable metatarsophalangeal joint, these 
forces would likely affect the metatarsophalangeal joint, leading to HV instead of HV interphalangeus [21, 22]. Another explanation is based on findings from some studies demonstrating a postoperative increase in radiographic measurements of the $\mathrm{HV}$ interphalangeus following correction of $\mathrm{HV}$, suggesting possible underestimation of $\mathrm{HV}$ interphalangeus due to pronation of the hallux in the foot with $\mathrm{HV}[24,25]$. A previous study by Strydom was the first to propose the concept of TVDH and evaluate the contribution of IPA to TVDH as $37.9 \%$, which was slightly lower than the contribution of $48.9 \%$ found in the present study [10]. This lower contribution of IPA in the study by Strydom et al. might be attributed to the biased cohort of their study consisting of patients who visited clinics for foot problems. Their cohort is assumed to have more subjects with $\mathrm{HV}$ than the general population. A possible underestimation of the HV interphalangeus due to pronation of the hallux in the foot with $\mathrm{HV}$ has been proposed [25]. In the present study, multivariable analysis was conducted to detect the independent influence of HV interphalangeus on the self-recognition of $\mathrm{HV}$, and IPA was detected as a negative factor for self-recognition, but its effect per unit increase was little compared to that of HVA.

Some limitations of our study must be considered in interpreting the results obtained. First, the present study adopted non-weightbearing foot radiographs instead of weightbearing ones. The difference in HVA measurement between weightbearing and non-weightbearing foot radiographs reported in previous studies are contradictory, with some researchers reporting no consistent change between two conditions [26], larger values under non-weightbearing conditions in normal or early HV, larger values under weightbearing conditions in advanced HV [27], or larger values under non-weightbearing conditions unrelated to the severity of HV [28]. Second, the present study was performed in limited areas, including two local towns, and might not reflect the situations in other areas. Although little has been clarified about the influencing factors on body image of $\mathrm{HV}$ in the general population, some factors besides those analyzed in the present study, such as educational, environmental, socioeconomic, psychological, and ethnocultural factors, might have the potential to affect self-recognition.

In conclusion, the present cross-sectional study is the first to show a discrepancy between self-recognition and radiographic diagnosis of HV in community-dwelling subjects. Valgus deformity at the metatarsophalangeal joint and female sex were independent positive factors for the self-recognition of $\mathrm{HV}$, but not for HV interphalangeus.

\section{Abbreviations}

HV, Hallux valgus; ROAD, Research on Osteoarthritis/Osteoporosis Against Disability; OA, osteoarthritis; HVA, HV angle; IPA, interphalangeal angle of the hallux; TVDH, total valgus deformity of the hallux

\section{Declarations}

\section{Ethics approval and consent to participate:}


The study was conducted in accordance with the Declaration of Helsinki and with the approval by the ethics committee of the University of Tokyo (no. 1264). Written informed consent was obtained from all the participants.

\section{Consent for publication:}

Not applicable

\section{Availability of data and materials:}

The data that support the findings of this study will not be shared, because the data were collected on the agreement from participants that the individual-level data will not be released and only aggregated data must be publicized.

\section{Competing interests:}

All authors declare no conflict of interests and disclose no financial or personal relationships with other people or organizations that could have an inappropriate effect on this work.

\section{Funding:}

This work was supported by a Grant-in-Aid from the Ministry of Health, Labour and Welfare: 19FA1401 (Director, Sakae Tanaka), 19FA0701 (Director, Hiroyuki Oka), and 19FA1901 (Director, Estuo Chosa). This work was also supported by JSPS KAKENHI Grant Numbers JP19H03895 and JP18K18447 to Noriko Yoshimura and JP19K19454 to Toshiko lidaka. This work was partly supported by grants from the Japan Agency for Medical Research and Development (17dk0110028h0001, Director, Noriko Yoshimura; 17gk0210007h0003, Director, Sakae Tanaka). This study was also partly supported by grants from the Mitsui Sumitomo Insurance Welfare Foundation (2016, Director, Noriko Yoshimura), the Japan Dairy Association (2017, Director, Noriko Yoshimura), Nakatomi Foundation (2019, Director, Toshiko lidaka), and Japan Osteoporosis Foundation (2019, Director, Toshiko lidaka). The funders had no role in the study design, data collection, analysis, interpretation, or preparation or submission of this work.

\section{Authors' contributions \}

Conception and design: TM, JH, YM, SHC, ST, NY; Analysis and interpretation of the data: TM, JH, YM, SHC; Drafting of the article: TM; Final approval of the article: All authors; Provision of study materials or patients: TI, CH, HO, SM, NY; Statistical expertise: HO; Obtaining of funding: TI, HO, ST, NY; Administrative, technical, or logistic support: TI, CH, HH, HY, MY, KN, ST, NY; Collection and assembly of data: JH, YM, $\mathrm{SHC}, \mathrm{TI}, \mathrm{CH}, \mathrm{HH}, \mathrm{HY}, \mathrm{NY}$ 


\section{Acknowledgements:}

The authors would like to thank Dr. Naoki Hirabayashi of the Kawakami Clinic in Hidakagawa Town, Mrs. Tomoko Takijiri, Mrs. Rie Takiguchi, Mrs. Kyoko Maeda, and other members of the town office in Hidakagawa town; Dr. Shinji Matsuda of the Shingu Public Health Centre; and Mrs. Tamako Tsutsumi, Mrs. Kanami Maeda, Mrs. Megumi Takino, Mrs. Shuko Okada, Mrs. Kazuyo Setoh, Mrs. Chise Ryouno, Mrs. Miki Shimosaki, Mrs. Chika Yamaguchi, Mrs. Yuki Shimoji, and other members of the town office in Taiji Town for their assistance in locating and scheduling participants for examinations. The authors wish to thank Ms. Kyoko Hattori, Mrs. Saeko Sahara, and Mr. Noriyuki Oe for their assistance in data reduction and administration.

\section{References}

1. Mann RA, Coughlin MJ. Hallux valgus-etiology, anatomy, treatment and surgical considerations. Clin Orthop Relat Res. 1981;157(157):31-41.

2. Menz HB, Lord SR. Foot pain impairs balance and functional ability in community-dwelling older people. J Am Podiatr Med Assoc. 2001;91(5):222-9.

3. Menz HB, Morris ME, Lord SR. Foot and ankle risk factors for falls in older people: a prospective study. J Gerontol A Biol Sci Med Sci. 2006;61(8):866 - 70.

4. Nix S, Smith M, Vicenzino B. Prevalence of hallux valgus in the general population: a systematic review and meta-analysis. J Foot Ankle Res. 2010;3:21.

5. Dunn JE, Link CL, Felson DT, Crincoli MG, Keysor JJ, McKinlay JB. Prevalence of foot and ankle conditions in a multiethnic community sample of older adults. Am J Epidemiol. 2004;159(5):491-8.

6. Nguyen US, Hillstrom HJ, Li W, Dufour AB, Kiel DP, Procter-Gray E, et al. Factors associated with hallux valgus in a population-based study of older women and men: the MOBILIZE Boston Study. Osteoarthritis Cartilage. 2010;18(1):41-6.

7. Nix SE, Vicenzino BT, Collins NJ, Smith MD. Characteristics of foot structure and footwear associated with hallux valgus: a systematic review. Osteoarthritis Cartilage. 2012;20(10):1059-74.

8. Yoshimura N, Muraki S, Oka H, Kawaguchi H, Nakamura K, Akune T. Cohort profile: research on Osteoarthritis/Osteoporosis Against Disability study. Int J Epidemiol. 2010;39(4):988 - 95.

9. Coughlin MJ, Saltzman CL, Nunley JA, 2nd. Angular measurements in the evaluation of hallux valgus deformities: a report of the ad hoc committee of the American Orthopaedic Foot \& Ankle Society on angular measurements. Foot Ankle Int. 2002;23(1):68-74.

10. Strydom A, Saragas NP, Ferrao PN. A radiographic analysis of the contribution of hallux valgus interphalangeus to the total valgus deformity of the hallux. Foot Ankle Surg. 2017;23(1):27-31.

11. Japanese Orthopaedic Association (JOA) Clinical Practice Guideline on the Management of Hallux Valgus (in Japanese). 2 Edition. Tokyo, Nankodo 2014. 
12. Nishimura A, Kato K, Fukuda A, Nakazora S, Yamada T, Uchida A, et al. Prevalence of hallux valgus and risk factors among Japanese community dwellers. J Orthop Sci. 2014;19(2):257 - 62.

13. Kato T, Watanabe S. The etiology of hallux valgus in Japan. Clin Orthop Relat Res. 1981;157(157):78-81.

14. Ferrari J. Bunions. BMJ Clin Evid. 2009;2009.

15. Adams PF, Hendershot GE, Marano MA. Current estimates from the National Health Interview Survey, 1996. Vital Health Stat 10. 1999(200):1-203.

16. Cho NH, Kim S, Kwon DJ, Kim HA. The prevalence of hallux valgus and its association with foot pain and function in a rural Korean community. J Bone Joint Surg Br. 2009;91(4):494-8.

17. Hardy RH, Clapham JC. Observations on hallux valgus; based on a controlled series. J Bone Joint Surg Br. 1951;33-B(3):376-91.

18. Koski K, Luukinen H, Laippala P, Kivela SL. Physiological factors and medications as predictors of injurious falls by elderly people: a prospective population-based study. Age Ageing. 1996;25(1):2938.

19. Barnett CH. Valgus deviation of the distal phalanx of the great toe. J Anat. 1962;96(Pt 2):171-7.

20. Gentili A, Masih S, Yao L, Seeger LL. Pictorial review: foot axes and angles. Br J Radiol. 1996;69(826):968 - 74.

21. Duke H, Newman LM, Bruskoff BL, Daniels R. Hallux abductus interphalangeus and its relationship to hallux abducto valgus. J Am Podiatry Assoc. 1982;72(12):625-8.

22. Coughlin MJ, Shurnas PS. Hallux rigidus: demographics, etiology, and radiographic assessment. Foot Ankle Int. 2003;24(10):731 - 43.

23. Bryant A, Tinley P, Singer K. A comparison of radiographic measurements in normal, hallux valgus, and hallux limitus feet. J Foot Ankle Surg. 2000;39(1):39-43.

24. Park JY, Jung HG, Kim TH, Kang MS. Intraoperative incidence of hallux valgus interphalangeus following basilar first metatarsal osteotomy and distal soft tissue realignment. Foot Ankle Int. 2011;32(11):1058-62.

25. Dixon AE, Lee LC, Charlton TP, Thordarson DB. Increased Incidence and Severity of Postoperative Radiographic Hallux Valgus Interphalangeus With Surgical Correction of Hallux Valgus. Foot Ankle Int. 2015;36(8):961-8.

26. Shereff MJ, DiGiovanni L, Bejjani FJ, Hersh A, Kummer FJ. A comparison of nonweight-bearing and weight-bearing radiographs of the foot. Foot Ankle. 1990;10(6):306 - 11.

27. Boszczyk A, Kwapisz S, Kiciński M, Kordasiewicz B, Liszka H. Non-weightbearing compared with weightbearing x-rays in hallux valgus decision-making. Skeletal Radiol. 2020;49(9):1441-7.

28. Fuhrmann RA, Layher F, Wetzel WD. Radiographic changes in forefoot geometry with weightbearing. Foot Ankle Int. 2003;24(4):326 - 31.

\section{Figures}




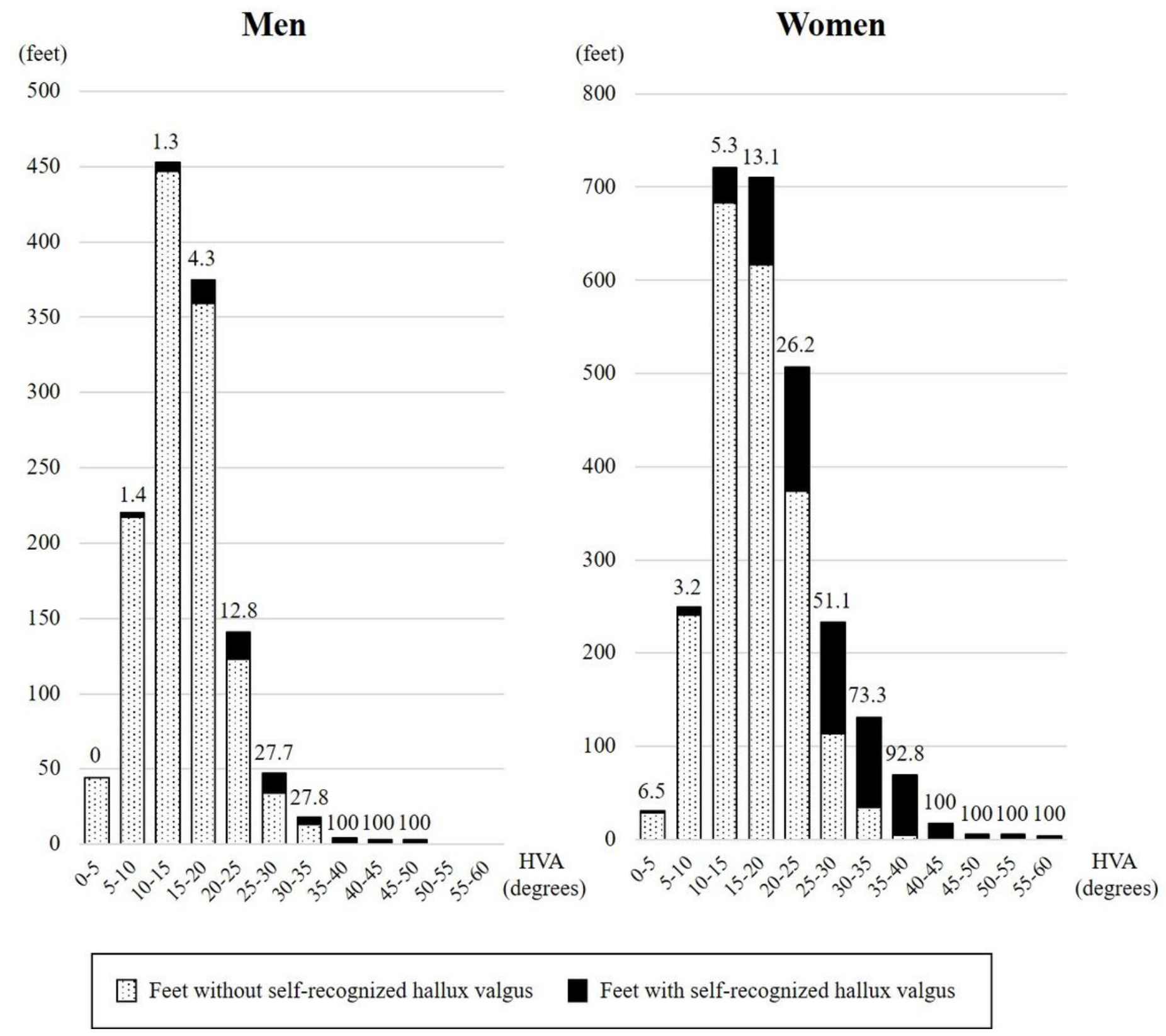

Figure 1

Histograms of the hallux valgus angle in feet with and without self-recognized hallux valgus. The number above each bar indicates the percentage of feet with self-recognized hallux valgus. HVA; hallux valgus angle. 